\title{
Influencia de las nanopartículas de Ag sobre las propiedades mecánicas y tribológicas y en el efecto citotóxico y bactericida de los recubrimientos de $\mathrm{TaN}(\mathrm{Ag})$
}

\author{
Aida M. Echavarría ${ }^{\mathrm{a}, \varpi}$, Sara Robledo ${ }^{\mathrm{b}}$, Gilberto Bejarano G. ${ }^{\mathrm{a}}$ \\ ${ }^{a}$ Centro de Investigación, Innovación y Desarrollo de Materiales - CIDEMAT, Facultad de Ingeniería, Universidad de Antioquia - \\ UdeA, Calle $70 \mathrm{~N}^{\circ}$ 52-21, Medellín, Colombia \\ ${ }^{\mathrm{b}}$ Programa de Estudio y Control de Enfermedades Tropicales - PECET, IMM-Facultad de Medicina, Universidad de Antioquia - \\ UdeA, Carrera 53 N N $^{\circ}$-30 SIU Laboratorio 632 Medellín, Colombia \\ $\triangle$ Autor para la correspondencia: aida.echavarria@udea.edu.co
}

Enviado: 18 Abril 2016; Aceptado: 16 Febrero 2017; Publicado on-Line: 22 Marzo 2017

RESUMEN: En este trabajo se desarrolló el recubrimiento compuesto de TaN(Ag) con una variación del contenido de plata entre 2,26 y 28,51\%at, mediante la técnica de pulverización catódica asistida por campo magnético desbalanceado. Se eligió el recubrimiento que presentó el mejor balance entre propiedades mecánicas y tribológicas, y se sometió a un ciclo de tratamientos térmicos con temperaturas entre $175^{\circ} \mathrm{C}$ y $275^{\circ} \mathrm{C}$ para producir la nucleación, el crecimiento y difusión controlada de las nanopartículas de Ag hasta la superficie del recubrimiento. Se verificó el tamaño y densidad de distribución de las nanopartículas en la superficie del recubrimiento, y su influencia en las propiedades mecánicas y tribológicas. Posteriormente se estudió el efecto bactericida frente a la bacteria $P$. aeruginosa mediante las pruebas de inhibición al crecimiento y de adherencia, así como el comportamiento citotóxico del material frente a osteoblastos humanos utilizando el método MTT. El recubrimiento TaN(Ag)-3 tratado térmicamente a $200{ }^{\circ} \mathrm{C}$ durante 4 min, incrementó la microdureza del acero inoxidable AISI 316L de 2,6 GPa a 10,7 GPa, y disminuyó la tasa de desgaste de $1,11 \times 10^{-3} \mathrm{~mm}^{3} / \mathrm{N} . \mathrm{m}$ a $0,17 \times 10^{-12} \mathrm{~mm}^{3} / \mathrm{N} . \mathrm{m}$. Este recubrimiento presentó $100 \%$ de viabilidad celular de osteoblastos, y un excelente comportamiento a la inhibición del crecimiento y adherencia de la bacteria $P$. aeruginosa.

PALABRAS CLAVE: Citotoxicidad; Efecto bactericida; Nanopartículas de Ag; Pulverización catódica; Recubrimientos biocompatibles

Cómo citar I Citation: Echavarría, A.M.; Robledo, S.; Bejarano G., G. (2017) "Influencia de las nanopartículas de Ag sobre las propiedades mecánicas y tribológicas y en el efecto citotóxico y bactericida de los recubrimientos de TaN(Ag)". Rev. Metal. 53(1): e085. http://dx.doi.org/10.3989/revmetalm.085

ABSTRACT: Influence of Ag nanoparticles on the mechanical and tribological properties and on the cytotoxic and bactericidal effects of $\mathrm{TaN}(\mathrm{Ag})$ coatings. In this work, a TaN $(\mathrm{Ag})$ composite coating with different silver contents between 2.26 and $28.51 \%$ at, were developed by the unbalanced magnetron sputtering technique. The coating with the best balance presented between tribological and mechanical properties was chosen, and it was subjected to thermal treatments cycles with temperatures among $175^{\circ} \mathrm{C}$ and $275{ }^{\circ} \mathrm{C}$ to allow the nucleation, growth and controlled diffusion of $\mathrm{Ag}$ nanoparticles up to the coating surface; the size, distribution and density of nanoparticles on the coating surface and their influence on the mechanical and tribological properties, were verified. The bactericidal effect against $P$. aeruginosa by growth inhibition and adhesion test was studied, as well as the cytotoxic behavior on osteoblasts by MTT test. The TaN(Ag)-3 coating after thermal treatment at $200{ }^{\circ} \mathrm{C}$ during $4 \mathrm{~min}$, increased the micro hardness of AISI 316 L stainless steel from $2.6 \mathrm{GPa}$ to $10.7 \mathrm{GPa}$, and decreased the wear rate from $1.11 \times 10^{-3} \mathrm{~mm}^{3} / \mathrm{N} . \mathrm{m}$ to $0.17 \times 10^{-12} \mathrm{~mm}^{3} / \mathrm{N} . \mathrm{m}$. This coating exhibited $100 \%$ of osteoblast cell viability, and an excellent performance to the inhibition of growth and adherence of $P$. aeruginosa.

KEYWORDS: Ag nanoparticles; Bactericidal effect; Biocompatible coatings; Citotoxicity; Magnetron sputtering

ORCID ID: Aida M. Echavarría (http://orcid.org/0000-0003-0614-4841); Sara Robledo (http://orcid.org/0000-00032752-4931); Gilberto Bejarano G. (http://orcid.org/0000-0001-9800-7259)

Copyright: (C) 2017 CSIC. Este es un artículo de acceso abierto distribuido bajo los términos de la licencia Creative Commons Attribution (CC BY) España 3.0. 


\section{INTRODUCCIÓN}

La modificación superficial a partir del dopaje de recubrimientos de nitruros metálicos nanocristalinos como el TaN, ZrN, TiN, MoN, CrN y NbN, caracterizados por su alta estabilidad química y excelentes propiedades mecánicas, con nanopartículas de metales dúctiles como la Ag, (Manninen et al., 2011), surgen como alternativa para aplicaciones donde se requiere mejorar la resistencia al desgaste y el desempeño de algunos aceros inoxidables, titanio y aleaciones de titanio, entre otros. A la buena biocompatibilidad de los nitruros mencionados y su elevada dureza se suma el efecto auto-lubricante y bactericida de las nanopartículas, potenciando aún más sus aplicaciones (Muratore et al., 2007; Echeverrigaray et al., 2016; Falconer y Grainger, 2017). Las propiedades mecánicas y el efecto bactericida del material compuesto mejoran ostensiblemente, siempre y cuando el tamaño de las partículas embebidas en la matriz sea inferior a $100 \mathrm{~nm}$ (Misra et al., 2012; Madhuree et al., 2016).

Los iones metálicos como $\mathrm{Ag}^{+}, \mathrm{el} \mathrm{Cu}^{2+}$ y el $\mathrm{Ni}^{2+}$ han mostrado un efecto positivo para el control de la adherencia y la proliferación de diferentes tipos de bacterias; esta facultad actualmente viene aprovechándose para evitar la colonización de las mismas en componentes poliméricos y metálicos utilizados en el hogar, en la industria textil, en centros hospitalarios (Gopinath y Velusamy, 2013), así como también en el diseño de dispositivos de liberación controlada de fármacos de última generación y la fabricación de implantes (Chang et al., 2012; Taoyu et al., 2015; Wang et al., 2016;). Un ejemplo de ello es el estudio de la implantación de iones de plata en aceros inoxidables y matrices cerámicas, para la reducción de la adherencia bacteriana y posterior formación de biofilm de cepas como $E$. coli $y$ $S$. aureos en dispositivos biomédicos y de $P$. aeruginosa en instrumentación quirúrgica (Echeverrigaray et al., 2016; Tallósy et al., 2016).

Para garantizar un elevado efecto bactericida y una apropiada biocompatibilidad en el material compuesto, debe mantenerse el equilibrio entre la cantidad, distribución y forma de nanopartículas de $\mathrm{Ag}$ presentes en la matriz del recubrimiento y la liberación de iones de $\mathrm{Ag}^{+}$al medio circundante, de tal forma que se induzca a la muerte de las bacterias o se inhiba su adherencia, sin afectar la viabilidad celular, es decir, sin ser citotóxico (Tianlu et al., 2014). El mecanismo más discutido por medio del cual la plata ejerce su efecto bactericida, consiste en el enlace que forman los iones de $\mathrm{Ag}^{+}$con moléculas biológicas o grupos funcionales de las paredes celulares de las bacterias, las cuales contienen oxígeno, azufre y nitrógeno que se caracterizan por ser donantes fuertes de electrones (Wei and Chu, 2008); una vez allí, los iones $\mathrm{Ag}^{+}$tienen la capacidad de desplazar otros elementos como el $\mathrm{Ca}$ y el
Zn que son necesarios para la supervivencia de los microorganismos, ocasionando por ende la muerte de la bacteria. Por ello se hace necesario que la cantidad de plata sea la requerida para contrarrestar la acción bacteriana sin afectar la viabilidad celular (Chang et al., 2012; Tianlu et al., 2014).

Acorde a lo anterior, este trabajo tiene como objetivo, evaluar inicialmente la influencia del contenido de $\mathrm{Ag}$ de los recubrimientos nanocompuestos de $\mathrm{TaN}(\mathrm{Ag})$ sobre la microestructura y sobre las propiedades mecánicas y tribológicas, una vez realizado esto se seleccionó el sistema de recubrimiento con el mejor balance microdureza/tasa de desgaste y se sometió a un ciclo de tratamientos térmicos en un rango de temperaturas entre 175 y $275^{\circ} \mathrm{C}$ durante 4 min; allí se evaluó el tamaño, forma y distribución de las nanopartículas de Ag que emergieron a la superficie del compuesto. A la muestra tratada térmicamente que presentó la mejor distribución y el menor tamaño de partículas de plata, se le evaluó el efecto bactericida frente a la bacteria $P$. aeruginosa, y el carácter citotóxico frente a osteoblastos humanos.

\section{MATERIALES Y MÉTODOS}

\subsection{Deposición de recubrimientos y tratamiento térmico}

Los recubrimientos se depositaron sobre muestras de acero inoxidable AISI 316L y obleas de Silicio unidireccional (100) mediante la técnica de pulverización catódica asistida por campo magnético desbalanceado, previamente desengrasadas en un baño de ultrasonido en una solución de acetona y propanol. Una vez en la cámara de pulverización, las muestras se sometieron a una limpieza iónica con argón durante $30 \mathrm{~min}$. Previo a la deposición del sistema de recubrimientos $\mathrm{TaN}(\mathrm{Ag})$, los sustratos de acero fueron endurecidos superficialmente mediante un proceso de nitruración por plasma pulsado, utilizando una atmosfera de argón/nitrógeno/ hidrógeno, a una presión de $6,3 \times 10^{-1} \mathrm{mbar}$, un voltaje bias de $-750 \mathrm{~V}$ y a una temperatura de $380{ }^{\circ} \mathrm{C}$ durante $9 \mathrm{~h}$. Posteriormente y con el fin de reducir la tensiones residuales en la interfase del acero inoxidable AISI $316 \mathrm{~L}$ y el recubrimiento por la diferencia de dureza (Liskiewicz et al., 2005), se depositó una monocapa de anclaje de tantalio de aproximadamente $70 \mathrm{~nm}$; una vez formada la capa de anclaje se procedió con el ingreso de nitrógeno para contribuir a la formación del nitruro de tantalio. Los recubrimientos de $\mathrm{TaN}(\mathrm{Ag})$ se realizaron según las condiciones descritas en la Tabla 1, en la cual se incluyen los espesores alcanzados para cada uno. Los substratos fueron posicionados a una distancia de $80 \mathrm{~mm}$ con respecto a dos blancos independientes de Ta y Ag con el 99,9\% de pureza, girando a una velocidad de $30 \mathrm{rpm}$. Por último se 
realizó la pulverización del blanco de Ta con una potencia de $1500 \mathrm{~W}$ y del blanco de Ag con potencias entre 30 y $210 \mathrm{~W}$ durante $4 \mathrm{~h}$ para formar el compuesto $\mathrm{TaN}(\mathrm{Ag})$ con los diferentes contenidos de plata.

Los recubrimientos fueron tratados térmicamente en un horno tipo mufla con atmósfera controlada de nitrógeno. Estos ciclos incluyeron temperaturas de $175^{\circ}, 200^{\circ}, 225^{\circ}, 250^{\circ}$ y $275^{\circ} \mathrm{C}$, cada una de ellas durante $4 \mathrm{~min}$, con enfriamiento inmediato mediante aire frio a presión. Este procedimiento permitió la difusión controlada de las nanopartículas de plata hasta la superficie, y de paso determinar la mejor relación de tamaño, forma y distribución de las nanopartículas de Ag sobre la superficie del recubrimiento, utilizando imágenes SEM de la superficie de las muestras y apoyados con el software ImageJ, como se discute más adelante en el apartado 3.2.1. En la Fig. 1a, se esquematiza la conformación del sistema multicapas del recubrimiento de $\mathrm{TaN}(\mathrm{Ag})$ depositado, así como el proceso de difusión de las nanopartículas de Ag, que toman forma de nano-wires y emergen hacia la superficie del recubrimiento a través de los límites de grano de la matriz de TaN, una vez realizado el tratamiento térmico (Fig. 1b).

TABla 1. Condiciones de deposición y espesor de los recubrimientos de $\mathrm{TaN}(\mathrm{Ag})$

\begin{tabular}{|c|c|c|c|}
\hline Recubrimiento $^{a}$ & $\begin{array}{c}\text { Potencia } \\
\text { blanco } \mathrm{Ag}(\mathrm{W})\end{array}$ & $\%$ at $\mathrm{Ag}$ & $\begin{array}{c}\text { Espesor } \\
(\mu \mathrm{m})\end{array}$ \\
\hline $\mathrm{TaN}(\mathrm{Ag})-1$ & 30 & 2,26 & $1,75 \pm 0,08$ \\
\hline $\mathrm{TaN}(\mathrm{Ag})-2$ & 50 & 7,15 & $2,25 \pm 0,07$ \\
\hline $\mathrm{TaN}(\mathrm{Ag})-3$ & 70 & 12,72 & $2,63 \pm 0,12$ \\
\hline $\mathrm{TaN}(\mathrm{Ag})-4$ & 120 & 20,05 & $3,47 \pm 0,13$ \\
\hline $\mathrm{TaN}(\mathrm{Ag})-5$ & 170 & 23,52 & $3,67 \pm 0,25$ \\
\hline TaN(Ag)-6 & 210 & 28,51 & $4,53 \pm 0,26$ \\
\hline
\end{tabular}

a Todos los recubrimientos fueron depositados a una presión de $4,4 \mathrm{X} 10^{-3} \mathrm{mbar}$, temperatura de $120^{\circ} \mathrm{C}$, Voltaje Bias $-70 \mathrm{~V}$, tasa de deposición entre 0,4 y $0,6 \mu \mathrm{m} . \mathrm{h}^{-1}$ y con una relación de $\mathrm{Ar} /$ $\mathrm{N}_{2}$ de $2,7 \mathrm{~cm}^{3} \mathrm{~min}^{-1}$

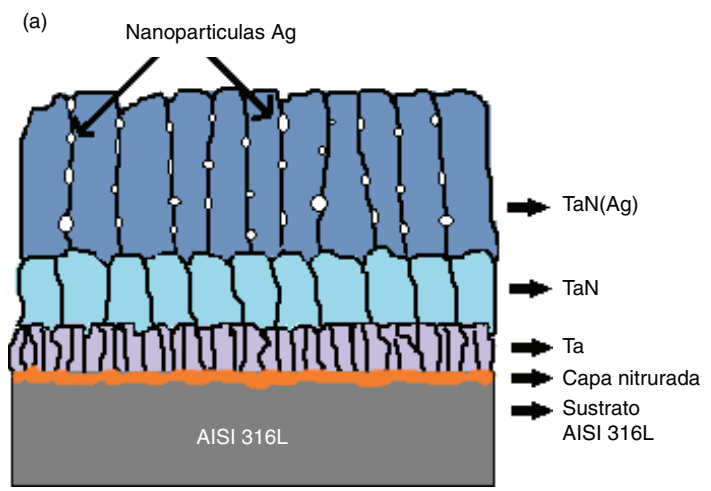

\subsection{Caracterización de los recubrimientos}

\subsubsection{Evaluación de la morfología superficial, rugosidad, mojabilidad y análisis microestructural.}

La topografía superficial y la morfología transversal de los diferentes recubrimientos de $\mathrm{TaN}(\mathrm{Ag})$ se examinaron en un microscopio electrónico de barrido JEOL JSM-6490LV. La composición química de cada recubrimiento se determinó a partir de espectroscopia de energía dispersiva de rayos $\mathrm{X}$ (EDX) mediante el software INCA Energy. La formación de fases se caracterizó por difracción de rayos $\mathrm{X}$ en un equipo Panalytical Empyrean, en el modo de ángulo rasante, usando un ángulo de incidencia de $4^{\circ}$ y paso de $0,02^{\circ} / \mathrm{seg}$. La rugosidad de los recubrimientos se determinó por medio de un perfilómetro marca Bruker Pektakxt, con una fuerza de contacto de $3 \mathrm{mg}$, durante $30 \mathrm{~s}$ en un recorrido de 1500 micras, realizando 5 mediciones por muestra. Para determinar el grado de mojabilidad de los recubrimientos se determinó el ángulo de contacto por medio del equipo Rame-Hart contact angle \& tensiometer model 250. Para estimar la distribución y densidad de nanopartículas se realizó el análisis de frecuencia, la cual representa el número de partículas promedio con un rango de diámetro en un área superficial determinada utilizando el software ImageJ.

\subsubsection{Microdureza y comportamiento tribológico}

La dureza de los recubrimientos se determinó mediante el método de Knoop con un microdurómetro Shimadzu modelo HMV-G20, utilizando una carga de $0,245 \mathrm{~N}$ acorde a la norma ASTM C132613. El coeficiente de fricción y la tasa de desgaste se evaluaron mediante un tribómetro tipo "ball on disc", usando un contra cuerpo de alúmina de $6 \mathrm{~mm}$ de diámetro, carga de $1 \mathrm{~N}$, radio de la huella de $8 \mathrm{~mm}$, tiempo de $600 \mathrm{~s}$ y $70 \mathrm{rpm}$, acorde a la norma ASTM G99-95. Todas las mediciones se realizaron por triplicado y se llevaron a cabo a temperatura de

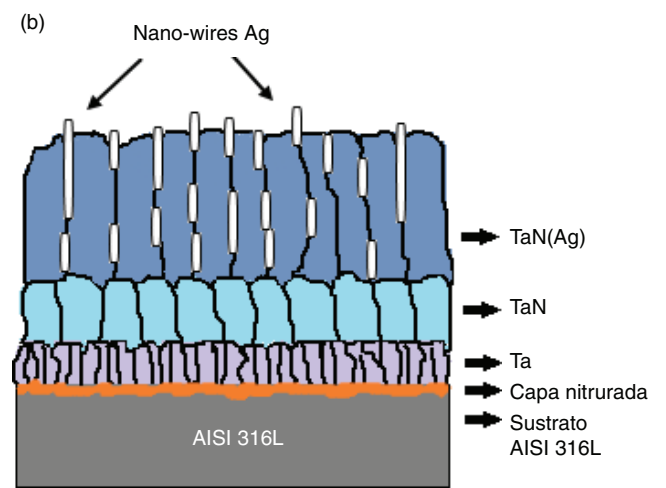

Figura 1. Esquema de la configuración del recubrimiento nanocompuesto TaN(Ag): a) antes y b) después del tratamiento térmico. 
$19 \pm 2{ }^{\circ} \mathrm{C}$ y a una humedad relativa de $48,5 \pm 2 \%$. Las muestras fueron lavadas previamente con etanol en un baño de ultrasonido y secadas con aire a presión. El volumen de desgaste fue determinado con un perfilómetro de contacto marca Bruker Pektakxt.

\subsection{Ensayos biológicos}

\subsubsection{Efecto bactericida}

Para la evaluación in vitro del efecto bactericida, se utilizaron muestras de silicio con el recubrimiento de $\mathrm{TaN}(\mathrm{Ag})$, con áreas $2 \mathrm{~cm}^{2}$ y como controles se utilizaron una muestra de silicio sin recubrir y un fragmento de vidrio, las cuales fueron previamente esterilizadas en autoclave a $120^{\circ} \mathrm{C}$ durante $21 \mathrm{~min}$. Se utilizaron muestras de silicio para esta evaluación, ya que las muestras de acero $316 \mathrm{~L}$ presentaron un área superficial muy grande de $5 \mathrm{~cm}^{2}$, que requerían de una gran cantidad de pozos y encarecían demasiado el costo del ensayo.Los ensayos de actividad antibacterial fueron llevados a cabo siguiendo la guía "OECD Quantitative Method for evaluating bactericidal efficacy of biocides use on hard surfaces (draft) y Jappanese Industrial Standard Antimicrobial products - test for antimicrobial activity and efficacy, JIS Z 208.2000”. Las muestras fueron expuestas a la bacteria $P$. aeruginosa (cepa ATCC $^{\circledR} 27853 \mathrm{TM}$ ) (American Type Cell Collection, Manassas, VA, USA), y se determinó la inhibición al crecimiento y la adherencia de las mismas sobre las diferentes superficies. La cepa $P$. aeruginosa se sembró en un caldo de BHI (Becton, Dickinson Co, StLakes, NJ, USA) y se incubó durante $24 \mathrm{~h}$ a $37{ }^{\circ} \mathrm{C}$; posteriormente se sembraron en placas con agar nutritivo (ICMT, Sabaneta, Colombia) durante $24 \mathrm{~h}$ a $37^{\circ} \mathrm{C}$, con el fin de obtener colonias aisladas para la preparación del inóculo. De cada placa de cultivo se seleccionó una o dos colonias aisladas con morfología similar, las cuales se resuspendieron en $3 \mathrm{ml}$ de solución salina estéril. De esta manera se obtuvo una turbidez ajustando al patrón 0,5 de la escala de Mc Farland (por comparación visual con el estándar), correspondiente a una concentración de aproximada de 1 a 2 × $10^{8} \mathrm{UFC} / \mathrm{ml}$. Se realizó un recuento de colonias crecidas sobre el material luego de 24 h de incubación.

\subsubsection{Prueba de inhibición del crecimiento bacte- riano. Para la realización de esta prueba se adi- cionaron $100 \mu \mathrm{l}$ del inóculo de bacterias ajustado al 0,5 de Mc Farland en $100 \mathrm{ml}$ de Agar LB a $37^{\circ} \mathrm{C}$, se homogenizó y se sirvieron $20 \mathrm{ml}$ del medio de cultivo conteniendo la cepa bacteriana en cajas de Petri. Las muestras de silicio con y sin recubri- miento y previamente esterilizadas por autoclave, se colocaron en el centro de la caja y se dejaron en una cabina de flujo hasta su gelificación, seguidamente se incubaron durante $24 \mathrm{~h}$ a $37^{\circ} \mathrm{C}$. Después de la}

incubación, se examinó cada caja y se visualizaron las colonias formadas (UFC) que crecieron sobre el material. Las pruebas de inhibición se realizaron por triplicado para asegurar la confiabilidad en los resultados.

2.3.1.2. Prueba de adherencia bacteriana en los recubrimientos. Una vez esterilizadas las muestras en un autoclave a $120{ }^{\circ} \mathrm{C}$ durante $30 \mathrm{~min}$, se depositó una muestra de cada recubrimiento en una caja de Petri estéril, luego se adicionaron $20 \mu \mathrm{ldel}$ inóculo de bacterias preparado conteniendo 1 a $2 \times 10^{8} \mathrm{UFC} / \mathrm{ml}$ y se dispersaron sobre la superficie de cada material. Los materiales expuestos a la suspensión de bacterias $P$. aeruginosa se incubaron durante $1 \mathrm{~h}$ a $37^{\circ} \mathrm{C}$. Después de la incubación, se examinó cada placa y se visualizaron las UFC de colonias de las bacterias que crecieron sobre los recubrimientos tratados térmicamente. Adicionalmente, cada muestra se depositó en un tubo que contenía $3 \mathrm{ml}$ de solución salina estéril para su lavado por agitación. Posteriormente cada pieza de material se retiró y se fijó para su análisis por microscopia electrónica de barrido. Mediante esta técnica se analizó la superficie de los recubrimientos y la interacción de las bacterias con la misma. Las pruebas de adherencia bacteriana se realizaron por triplicado para asegurar la reproducibilidad.

\subsubsection{Citotoxicidad}

La citotoxicidad del recubrimiento se evaluó acorde a la guía ISO 10993-5:2009(E) Biological evaluation of medical devices Part 5: test for in vitro cytotoxicity", mediante el método MTT (bromuro de 3-(5,4 dimetil tizol-2-I) -2-5 difeniltretrazolium), reactivo que permite medir la actividad de la deshidrogenasa mitocondrial, detectando la producción de formazán debido a la actividad metabólica de células vivas y activas. Para esta prueba, se utilizaron osteoblastos humanos de la línea celular Saos-2 (ATCC®HTB-85) a una densidad de 100.000 células. $\mathrm{cm}^{-2}$ y se cultivaron en presencia de cada recubrimiento durante $72 \mathrm{~h}$ a $37^{\circ} \mathrm{C}$ y $5 \%$ $\mathrm{CO}_{2}$. El material se retiró y las células se incubaron en presencia de $200 \mathrm{uL}$ del reactivo a una concentración de $5 \mathrm{mg} . \mathrm{mL}^{-1}$ y los platos se incubaron nuevamente durante $4 \mathrm{~h}$ en las mismas condiciones. Luego se adicionó en cada pozo $200 \mu \mathrm{L}$ de Solución de parada compuesta por isopropanol al 50\% y $10 \%$ de SDS (dodecilsulfato sódico) y se incubaron las células nuevamente durante 30 minutos a temperatura ambiente. La viabilidad celular se determinó con base en la cantidad de formazán producido de acuerdo a la intensidad de color (absorbancia) registrada como Densidades Ópticas (D.O) obtenidas a $570 \mathrm{~nm}$ en un espectrofotómetro (Varioskan ${ }^{\mathrm{TM}}$ Flash Multimode Reader - Thermo Scientific, USA). Se utilizaron células cultivadas en medio de cultivo 
solo (en ausencia de material) como control de viabilidad. La citotoxicidad se determinó de acuerdo a los porcentajes de viabilidad y mortalidad obtenidos para cada condición experimental. El porcentaje de viabilidad se calculó con la Ec. (1):

$\%$ Viabilidad $=(\mathrm{D} . \mathrm{O}$ células expuestas al material $) /(\mathrm{D} . \mathrm{O}$ células control $) \times 100$

donde la D.O de las células control corresponden al 100\% de viabilidad. A su vez, el porcentaje de mortalidad se calculó con la Ec. (2):

$\%$ Mortalidad $=100-\%$ viabilidad para el material.

Los ensayos de citotoxicidad se realizaron por triplicado en dos experimentos aislados. Todas las muestras fueron esterilizadas en un autoclave a
$120{ }^{\circ} \mathrm{C}$ durante $30 \mathrm{~min}$, previo a realizar la prueba de citotoxicidad.

\section{RESULTADOS Y DISCUSIÓN}

\subsection{Morfología superficial, microdureza y comportamiento tribológico de los recubrimientos}

En la Fig. 2 se muestran las imágenes SEM de la sección transversal de los recubrimientos TaN(Ag). En las Fig. 2 (a-b) correspondiente a los recubrimientos de $\mathrm{TaN}(\mathrm{Ag})-1$ y $\mathrm{TaN}(\mathrm{Ag})-2$, se observa la formación de una estructura densa columnar, de grano fino con cúpulas globulares (Liu et al., 2017). En la Fig. 2c para el recubrimiento (a)

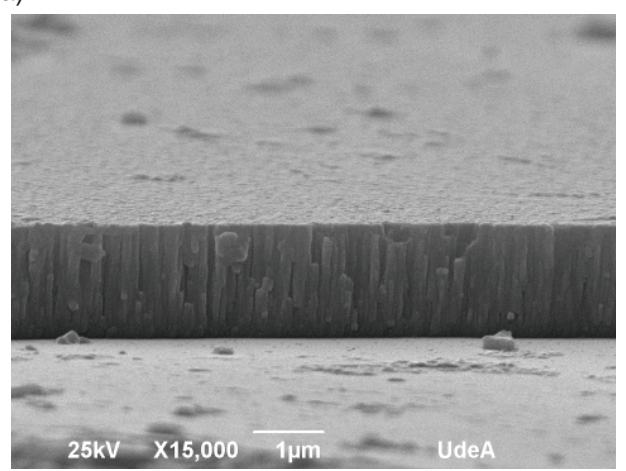

(c)

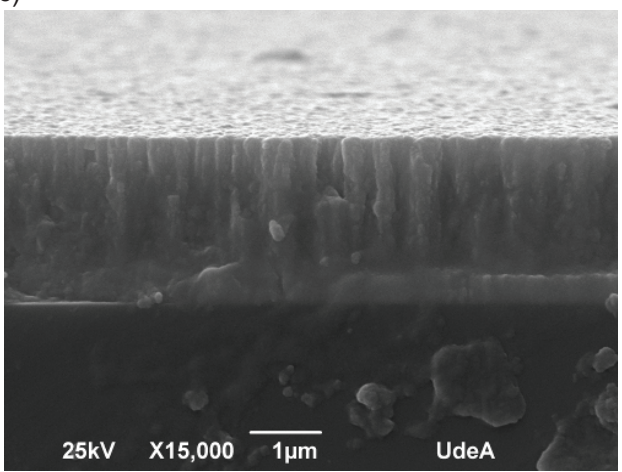

(e)

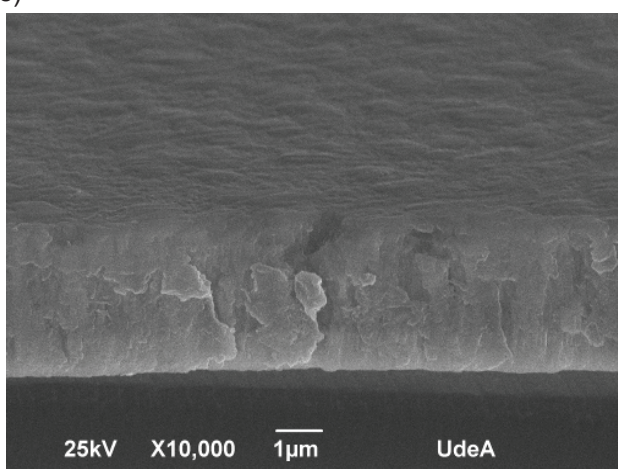

(b)

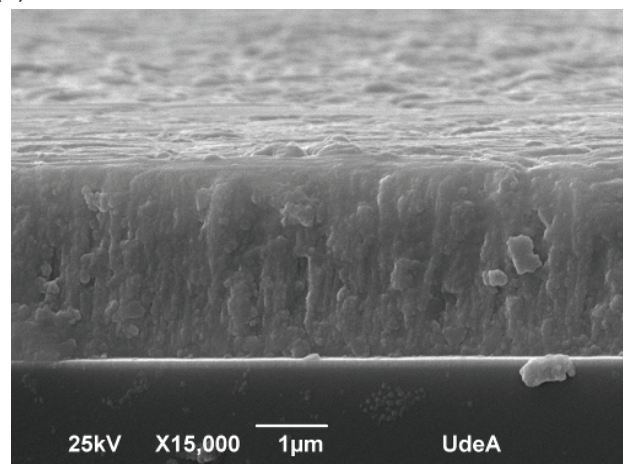

(d)

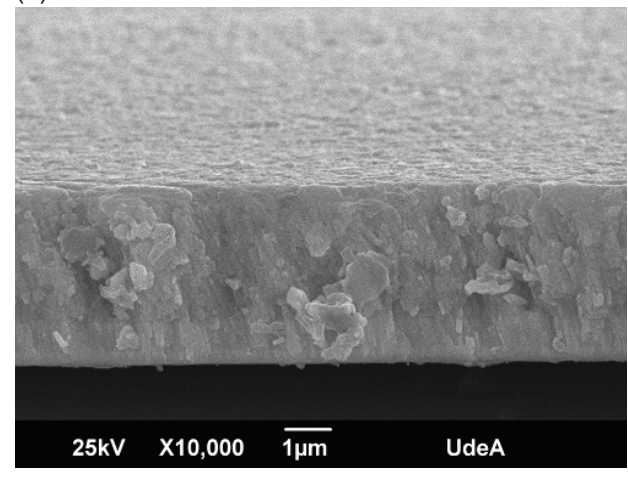

(f)

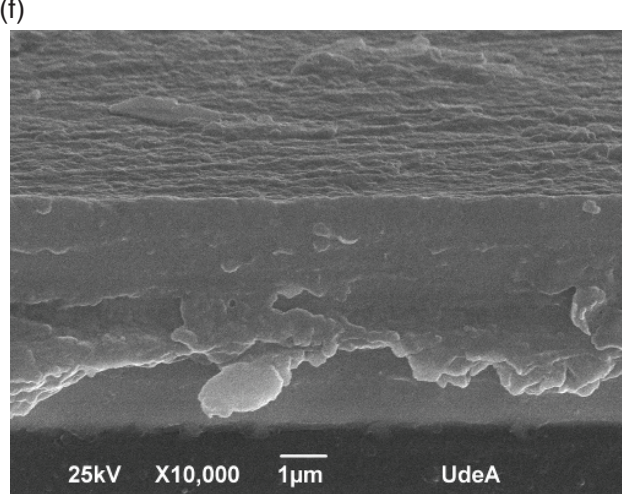

FIGURA 2. Imagen SEM de sección transversal de los recubrimientos TaN (Ag) con tratamientos térmicos y depositados con diferentes potencias aplicadas al blanco de Ag: a) TaN(Ag)-1, b) TaN(Ag)-2, c) TaN(Ag)-3, d) TaN(Ag)-4, be) TaN(Ag)-5 y f) $\operatorname{TaN}(\mathrm{Ag})-6$. 
TaN(Ag)-3, la estructura columnar ya no es tan definida como las dos anteriores, resultando en una estructura más densa y compacta, el mismo fenómeno se presenta para recubrimientos con cantidades de Ag superiores a $120 \mathrm{~W}$ en los recubrimientos TaN(Ag)-4, 5 y 6.

El fenómeno de densificación de los recubrimientos con el incremento de material dopante, es debido fundamentalmente a que el metal de transición de baja dureza difunde a través de los límites de grano columnar de la matriz TaN, coalesciendo y conduciendo a la deformación de la estructura y de paso al reacomodamiento del compuesto (Bhatnagar et al. 2017).

Los perfiles de microdureza y propiedades tribológicas se muestran en la Fig. 3. En la Fig. 3a, la mayor microdureza corresponde a la muestra $\mathrm{TaN}(\mathrm{Ag})-1$, sin embargo es el recubrimiento que presenta la mayor tasa de desgaste, Fig. 3b. El recubrimiento $\mathrm{TaN}(\mathrm{Ag})-3$ presenta la menor tasa de desgaste de todos los sistemas fabricados y un coeficiente de fricción muy por debajo de los aceros inoxidables de uso común en aplicaciones biomédicas, al igual que la microdureza. Esta muestra se toma como referencia para la realización de los tratamientos térmicos posteriores a temperaturas entre $175^{\circ} \mathrm{C}$ y $275^{\circ} \mathrm{C}$.

\subsection{Caracterización del recubrimiento TaN(Ag)-3}

\subsubsection{Tratamientos térmicos}

El recubrimiento $\mathrm{TaN}(\mathrm{Ag})-3$ que presentó el mejor balance entre propiedades mecánicas y tribológicas fue tratado térmicamente a temperaturas de $175^{\circ} \mathrm{C}, 200{ }^{\circ} \mathrm{C}, 225^{\circ} \mathrm{C}, 250{ }^{\circ} \mathrm{C}$ y $275^{\circ} \mathrm{C}$, cada una de ellas durante $4 \mathrm{~min}$. Este procedimiento permitió la difusión controlada de las nanopartículas de plata hasta la superficie, y de paso determinar la mejor relación de tamaño, forma y distribución de las nanopartículas de Ag sobre la superficie del recubrimiento, utilizando las imágenes SEM que se muestran en la Fig. 4.

En la Fig. 5 se muestran los diámetros promedio de las nanopartículas vs la frecuencia expresada en número de nanopartículas, para el recubrimiento $\mathrm{TaN}(\mathrm{Ag})-3$ tratado térmicamente a $175^{\circ} \mathrm{C}, 200^{\circ} \mathrm{C}$ y $225^{\circ} \mathrm{C}$, en los cuales se aprecia una gran cantidad de nanopartículas (elevada frecuencia) que difundieron hacia la superficie del compuesto y presentaron diámetros inferiores a los $100 \mathrm{~nm}$. Se pueden observar también aglomerados de Ag con diámetros que oscilan entre 200 y $400 \mathrm{~nm}$, debido a fenómenos de coalescencia, acorde con (Rycenga et al., 2011; Bhatnagar et al., 2017), muy particularmente para la muestra tratada a $225^{\circ} \mathrm{C}$. Acorde a ello se seleccionó el ciclo a $200{ }^{\circ} \mathrm{C}$ durante 4 min como el óptimo debido a la mayor frecuencia de nanopartículas con un tamaño menor a $100 \mathrm{~nm}$, y que presentaron una distribución apropiada sobre toda la superficie del recubrimiento. Una vez realizada ésta evaluación se procedió con los ensayos de carácter biológico.

\subsubsection{Análisis químico y formación de fases}

En la Tabla 2 se muestran los resultados de EDX realizado al recubrimiento $\mathrm{TaN}(\mathrm{Ag})-3$ tratado térmicamente a diferentes temperaturas. Los porcentajes atómicos de la $\mathrm{Ag}$ se incrementaron después del tratamiento térmico, debido al proceso de difusión de las nanopartículas de Ag hacia la superficie de los recubrimientos (Bai et al., 2016), lo que favorece un enriquecimiento de $\mathrm{Ag}$ a nivel superficial en la matriz de TaN. El proceso de difusión tiene lugar mediante dos etapas, la primera de ellas es la difusión de átomos de Ag que se encuentran a unos cuantos nanómetros de la superficie, los cuales al encontrarse con otros forman clústeres; éste proceso
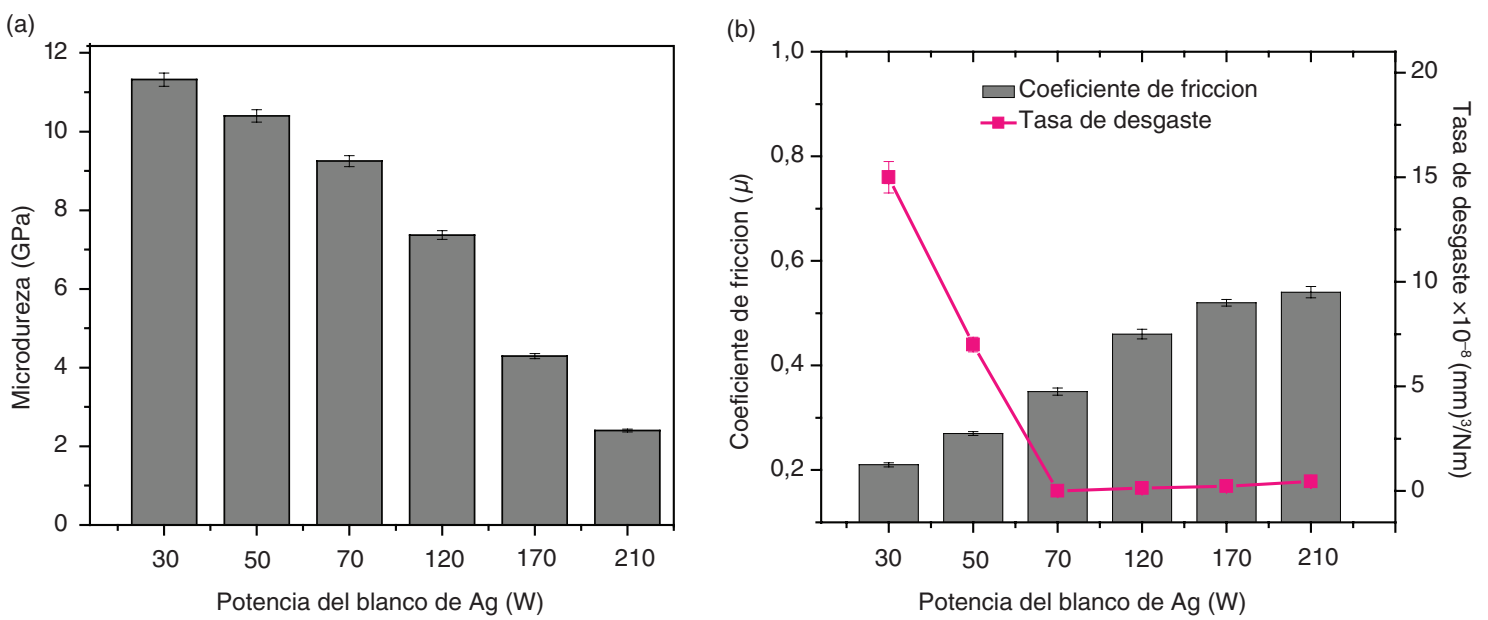

FIgURA 3. Microdureza y propiedades tribológicas de los recubrimientos de TaN(Ag): a) Microdureza vs potencia del blanco de Ag, y b) coeficiente de fricción y tasa de desgaste vs potencia del blanco de Ag. 
(a)

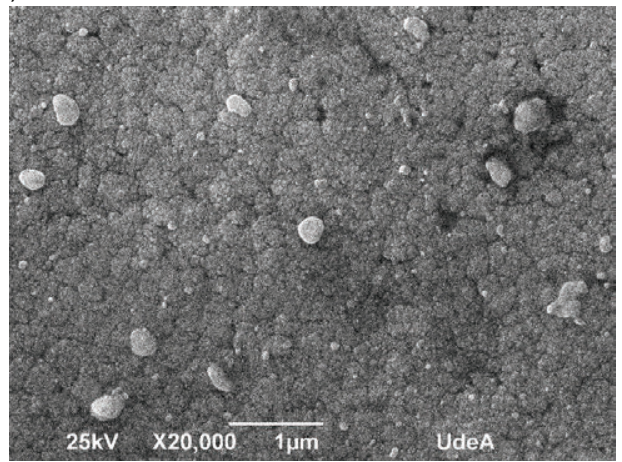

(c)

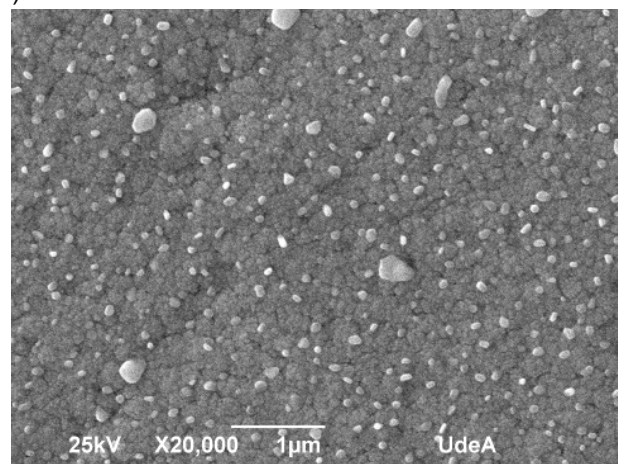

(b)

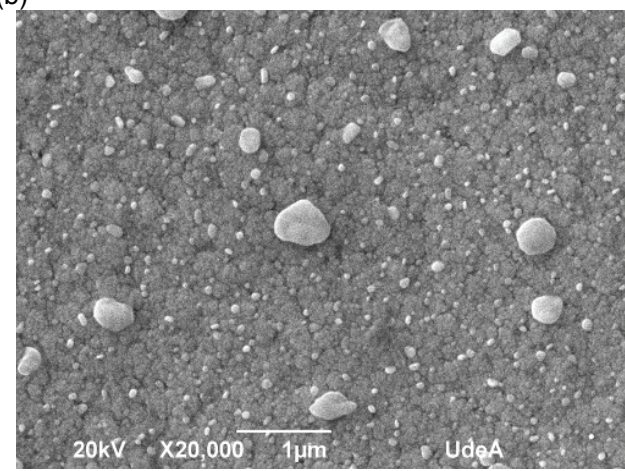

(d)

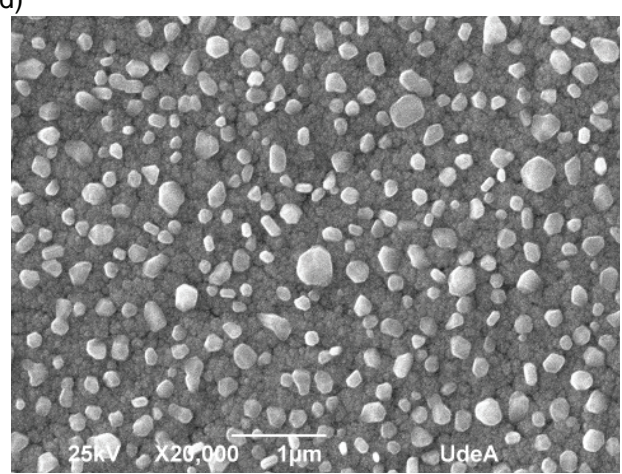

(e)

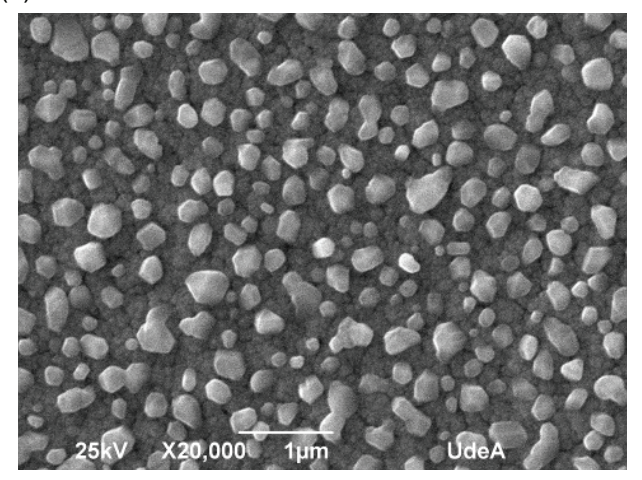

FIGURA 4. Difusión y formación de nanopartículas de Ag sobre la superficie de los recubrimientos de TaN(Ag)-3 después del tratamiento térmico por $4 \mathrm{~min}$ : a) $175^{\circ} \mathrm{C}$, b) $200{ }^{\circ} \mathrm{C}$, c) $225^{\circ} \mathrm{C}$, d) $250{ }^{\circ} \mathrm{C}$ y e) $275^{\circ} \mathrm{C}$.

se da a bajas temperaturas, donde la energía de activación del sistema es baja. Con el incremento de la temperatura y el aumento de la energía de activación en el sistema, se da el inicio de una segunda etapa de difusión por medio de la cual la conversión de los clusters a nanopartículas, hace que éstas últimas emerjan a la superficie entre las fronteras o límites de grano de la matriz de TaN.

Los difractogramas del recubrimiento TaN(Ag)-3 tratado a diferentes temperaturas se muestran en la Fig. 6; allí puede observarse la formación predominante de la fase cúbica del TaN en la dirección [111], $\mathrm{y}$ con menor intensidad en las direcciones [200 y 220]. En todos los recubrimientos se pudo observar que la Ag aparece en picos independientes, dado que éste elemento es inmiscible en la matriz de TaN. La dirección [220] de Ag, presenta muy baja intensidad en todos los recubrimientos. Sin embargo, el pico de Ag en la dirección [111] presenta una mayor intensidad indicando una fuerte texturización en dicha dirección, lo cual está probablemente asociado al crecimiento de las nanopartículas de Ag en esa dirección y su enriquecimiento en la superficie con la temperatura del tratamiento térmico, generando una señal más intensa en la difracción. Así mismo, el pico del TaN con crecimiento preferencial [111] disminuye a favor del pico del TaN en la dirección cristalográfica [200] con el aumento de la temperatura.

En la Fig. 7, se aprecian los resultados de microdureza, coeficiente de fricción y tasa de desgaste para el recubrimiento $\mathrm{TaN}(\mathrm{Ag})-3$ tratado térmicamente a diferentes temperaturas. En la Fig. 7a se observa que 

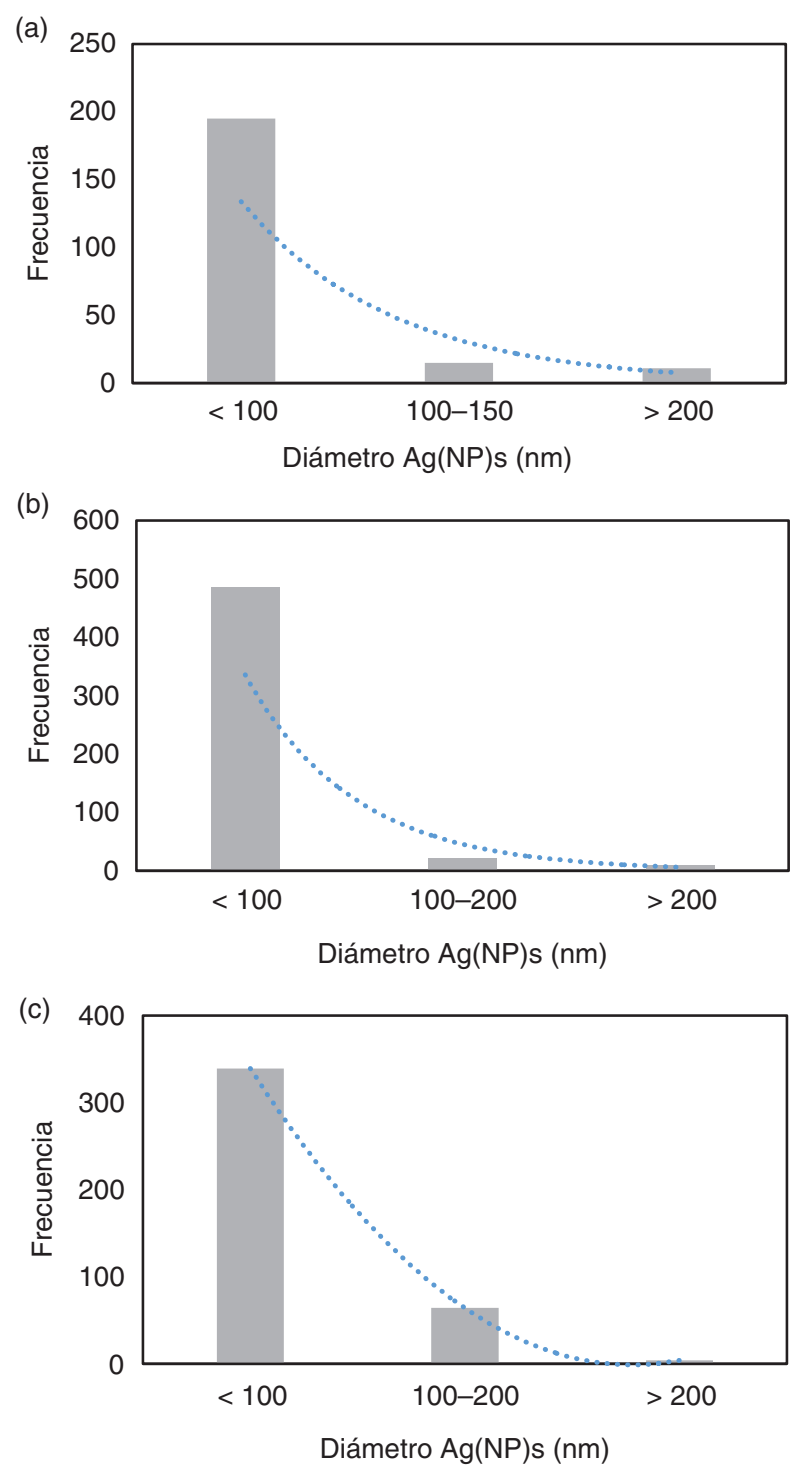

Figura 5. Frecuencia vs nanopartículas de Ag en la superficie del recubrimiento $\mathrm{TaN}(\mathrm{Ag})-3$ tratado térmicamente a diferentes temperaturas: a) 175 , b) $200{ }^{\circ} \mathrm{C}$ y c) $225^{\circ} \mathrm{C}$.

la dureza alcanza un valor máximo a una temperatura de $200{ }^{\circ} \mathrm{C}$, y luego disminuye continuamente con el aumento de la temperatura de tratamiento. Esto es debido probablemente a la deformación de la estructura del TaN y la inducción de tensiones residuales por el incremento de la plata a nivel superficial. Sin embargo, a temperaturas mayores a $200{ }^{\circ} \mathrm{C}$, la dureza disminuye debido al elevado contenido de plata que, por su baja dureza, contrarresta el efecto endurecedor obtenido inicialmente. En la Fig. $7 b$ se observa que el coeficiente de fricción y la tasa de desgaste disminuyen con el aumento de la temperatura, esto se debe a que a una mayor temperatura el contenido de Ag en la superficie es mayor, y allí se activan los procesos de auto-lubricación que ejercen las partículas de Ag, atribuido a
TABLA 2. Composición química del recubrimiento TaN(Ag)-3 tratado térmicamente a diferentes temperaturas

\begin{tabular}{lccc}
\hline \multicolumn{4}{c}{ Composición Química (\% at.) } \\
\hline \multirow{2}{*}{$\begin{array}{c}\text { Temperatura } \\
\left({ }^{\circ} \mathrm{C}\right)\end{array}$} & $\mathrm{Ta}$ & $\mathrm{N}$ & $\mathrm{Ag}$ \\
\cline { 2 - 4 } & 36,95 & 50,32 & 12,72 \\
175 & 15,79 & 65,4 & 18,81 \\
200 & 31,25 & 48,05 & 20,71 \\
225 & 32,22 & 46,79 & 20,99 \\
250 & 33,88 & 48,68 & 34,88 \\
$275^{\circ}$ & 24,30 & 38,18 & 37,52 \\
\hline
\end{tabular}

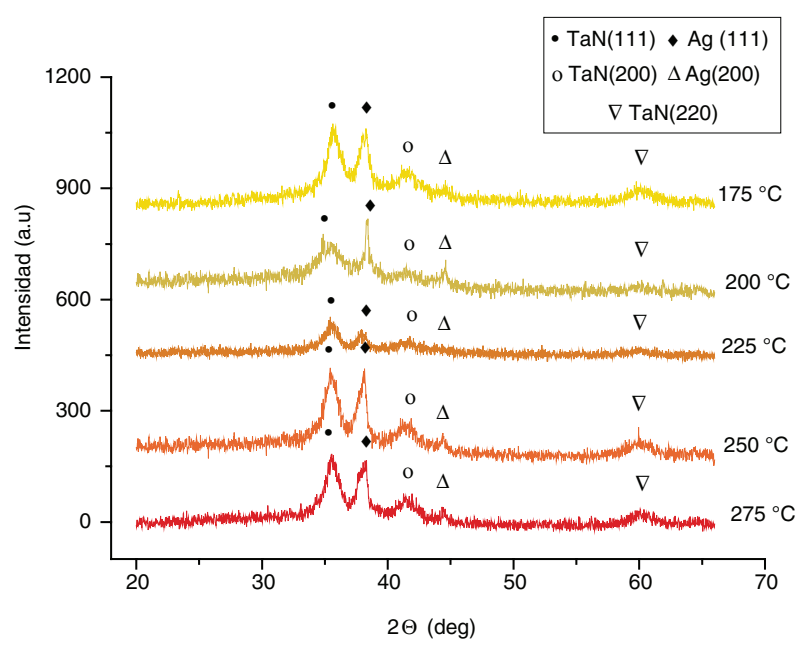

FIGURA 6. Difractogramas de rayos $\mathrm{X}$ del recubrimiento $\mathrm{TaN}(\mathrm{Ag})-3$ tratado térmicamente a diferentes temperaturas.

la ductilidad de este metal. Sin embargo, por encima de $200{ }^{\circ} \mathrm{C}$ la tasa de desgaste aumenta debido a la baja dureza del compuesto y baja adherencia que poseen estos recubrimientos, y que conducen a que el contracuerpo de alúmina entre en contacto con el sustrato en tiempos menores. Con base en los anteriores resultados la muestra $\mathrm{TaN}(\mathrm{Ag})-3$ tratada a $200{ }^{\circ} \mathrm{C}$ presentó la mayor dureza y menor tasa de desgaste y se seleccionó para la siguiente evaluación del comportamiento biológico.

\subsubsection{Mojabilidad y rugosidad}

En la Tabla 3, se relacionan los valores de los ángulos de contacto del recubrimiento $\mathrm{TaN}(\mathrm{Ag})-3$ con y sin tratamiento térmico, así como de una muestra de silicio sin recubrimiento y un fragmento de vidrio, como superficies control. El silicio y el vidrio poseen superficies de carácter hidrofílico, contrario al recubrimiento $\mathrm{TaN}(\mathrm{Ag})-3$, cuya superficie tiene un comportamiento hidrofóbico cuando se realiza el tratamiento térmico a la muestra. Este comportamiento está relacionado con la cantidad 

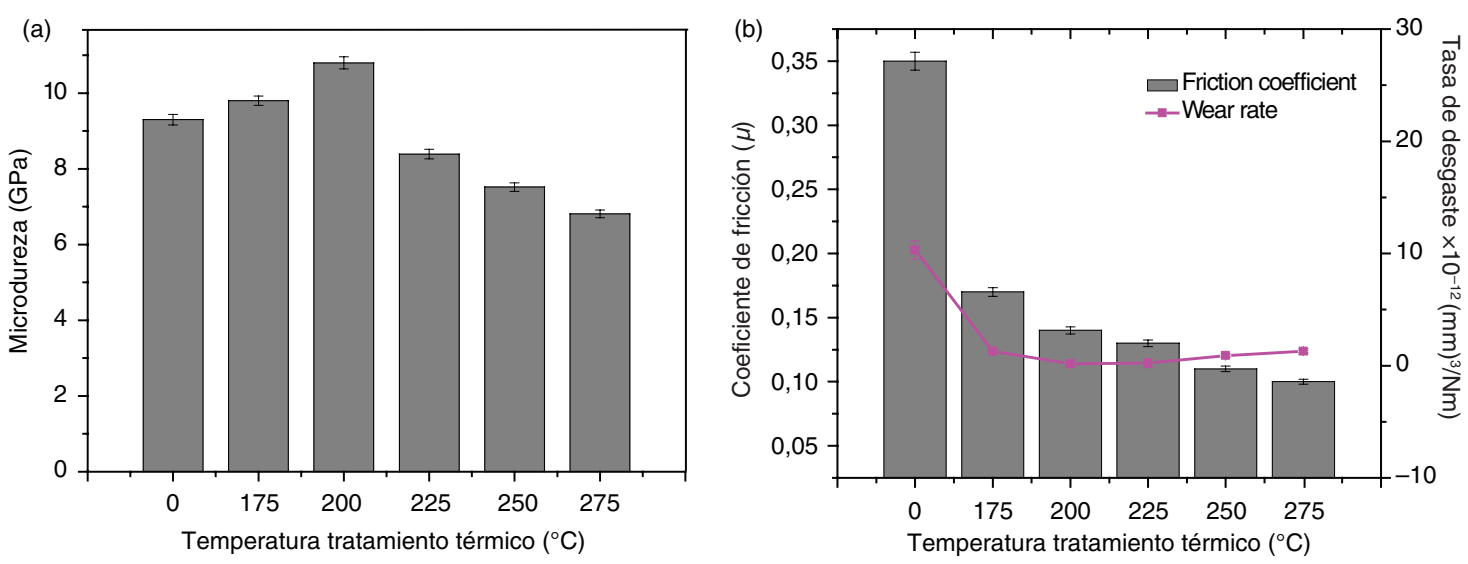

Figura 7. Microdureza y propiedades tribológicas de los recubrimientos de TaN(Ag): a) Microdureza vs temperatura de tratamiento térmico, y b) coeficiente de fricción y tasa de desgaste vs temperatura de tratamiento térmico.

TABLA 3. Valores de ángulo de contacto y rugosidad de los recubrimientos desarrollados con y sin tratamiento térmico

\begin{tabular}{|c|c|c|}
\hline Propiedad/Muestra & $\begin{array}{c}\text { Angulo de contacto } \\
\text { (agua) } \pm \mathrm{SD}\end{array}$ & $\begin{array}{l}\text { Rugosidad } \\
\text { (nm) }\end{array}$ \\
\hline $\operatorname{TaN}(\mathrm{Ag})-3^{\mathrm{b}}$ & $104,3 \pm 3,1$ & 22,3 \\
\hline $\operatorname{TaN}(\mathrm{Ag})-3^{\mathrm{c}}$ & $98,7 \pm 6,5$ & 21,0 \\
\hline Silicio & $65,7 \pm 3,2$ & 9,6 \\
\hline Fragmento de vidrio & $40,4 \pm 4,6$ & 4,2 \\
\hline
\end{tabular}

${ }^{\mathrm{b}}$ Tratamiento térmico $200{ }^{\circ} \mathrm{C}$ durante $4 \mathrm{~min} ;{ }^{\mathrm{c}} \mathrm{Sin}$ tratamiento térmico

de nanopartículas de plata difundidas hasta la superficie, que conllevan un incremento de la rugosidad (aunque sigue siendo de un valor nanométrico) y una reducción de la energía superficial del compuesto (Baghriche et al., 2012).

En la Fig. 8 se ilustra los resultados de la medición de ángulo de contacto del recubrimiento $\mathrm{TaN}(\mathrm{Ag})-3$, muestra de silicio y fragmento de vidrio. El grado de mojabilidad de las superficies es uno de los factores que influyen de forma directa, no solo en la fijación celular, sino también en el anclaje de bacterias y posterior formación de biofilm (Marques et al., 2016). Superficies hidrofílicas favorecen la adhesión bacteriana en comparación con las hidrofóbicas (Jiang et al., 2016). Por lo tanto la mojabilidad es una propiedad superficial del material que debe ser controlada apropiadamente acorde a la aplicación del mismo.

\subsubsection{Efecto bactericida de la muestra $\operatorname{TaN}(\mathrm{Ag})-3$}

3.2.4.1. Prueba de inhibición del crecimiento bacteriano. En la Fig. 9 se observa el comportamiento de la muestra TaN(Ag)-3 tratada térmicamente a $200{ }^{\circ} \mathrm{C}$ durante $4 \mathrm{~min}$, frente a la inhibición a la bacteria $P$. aeruginosa (Fig. 9a) después de un tiempo de incubación de $24 \mathrm{~h}$. Se puede ver que ésta muestra inhibe completamente el crecimiento de la bacteria, mientras que las muestras control de silicio y de vidrio permitieron el crecimiento de una gran cantidad de bacterias. Los resultados de esta evaluación indican que el recubrimiento de $\mathrm{TaN}(\mathrm{Ag})-3$ tratado térmicamente a $200{ }^{\circ} \mathrm{C}$ durante 4 min, presenta un importante efecto inhibitorio a la proliferación de la bacteria $P$. aeruginosa, el cual está muy asociado al efecto bactericida que ejercen las nanopartículas y los iones de plata, que se encuentran sobre la superficie del compuesto y que migran al medio de cultivo (Chernousova y Epple, 2013).

3.2.4.2. Prueba de adherencia bacteriana. La adherencia de $P$. aeruginosa en el recubrimiento $\mathrm{TaN}(\mathrm{Ag})-3$ tratado térmicamente a $200{ }^{\circ} \mathrm{C}$, se muestra en la Fig. 10a. Tanto en el recubrimiento como en la muestra de silicio y el fragmento de vidrio se observa una presencia escasa de $P$. aeruginosa, Fig 10 (b y c), respectivamente. Este comportamiento está posiblemente asociado a la baja rugosidad de éstos materiales (Tabla 2), que entre mayor sea, favorece la adhesión y fijación bacteriana (Truong et al. 2010). Por otro lado, los materiales o recubrimientos cuyas superficies presentan carácter hidrofóbico como el TaN(Ag)-3 tratado térmicamente, poseen también una baja energía superficial, que obstaculizan la adhesión o anclaje de la $P$. aeruginosa, sugiriendo un modo de acción bacteriostático del material, es decir que detiene el crecimiento del microorganismo produciendo una muerte lenta y evitando la proliferación bacteriana sobre la superficie y con ello, la posterior formación de colonias (Bowker, 2009), tal como se observa en los tres materiales de la Fig. 10.

Además de los mecanismos de interacción como las fuerzas de Van Der Waals y las propiedades hidrofílicas e hidrofóbicas del material, la rugosidad juega un rol fundamental en la adherencia bacteriana. Sin embargo la capacidad de adherencia de las bacterias, depende de la naturaleza del microorganismo, su morfología (forma, tamaño, 

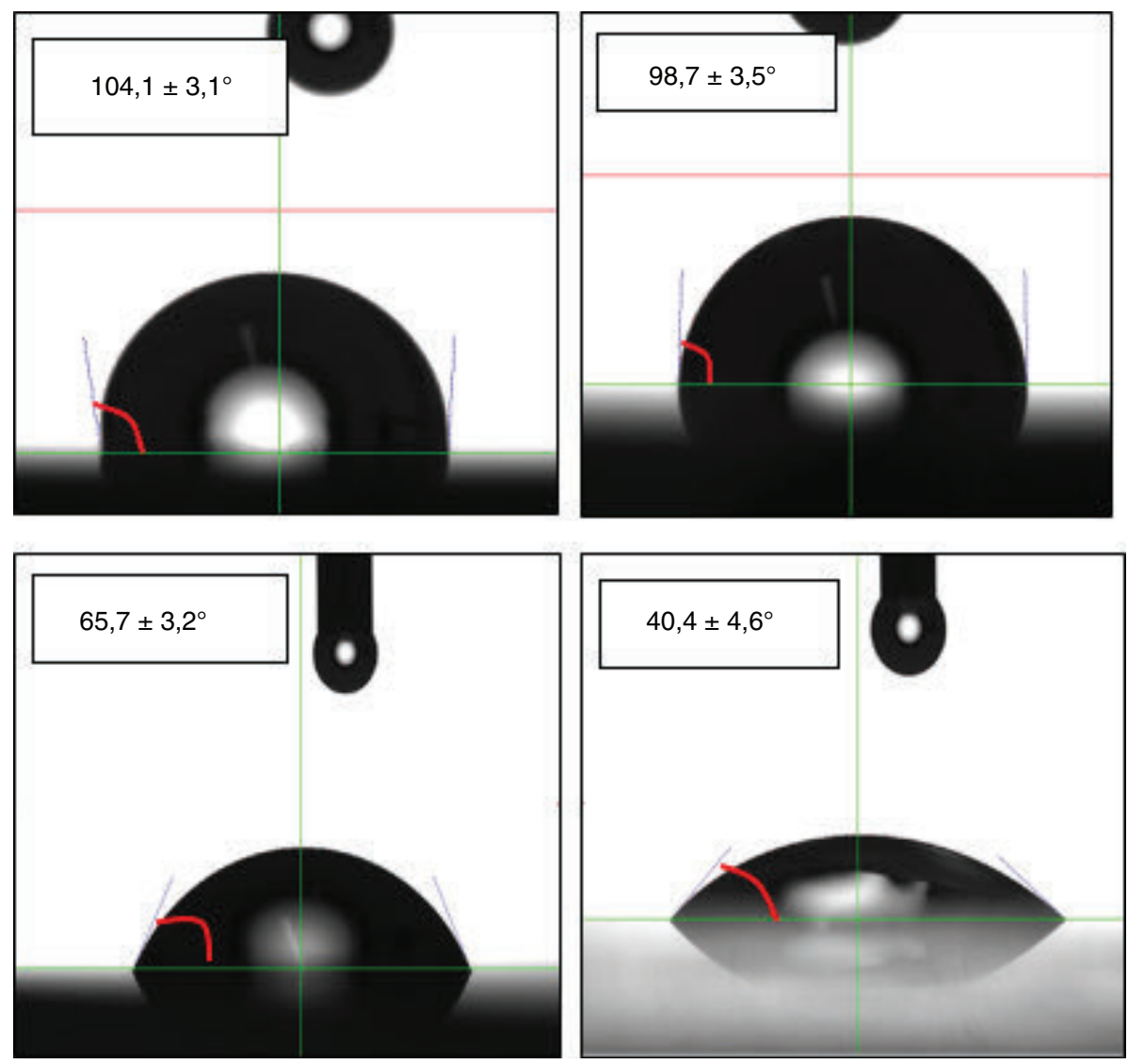

FIgura 8. Angulo de contacto (mojabilidad): a) TaN(Ag)-3 sin TT, b) TaN(Ag)-3 con TT, c) muestra de silicio sin recubrimiento y d) fragmento de vidrio.

(a)

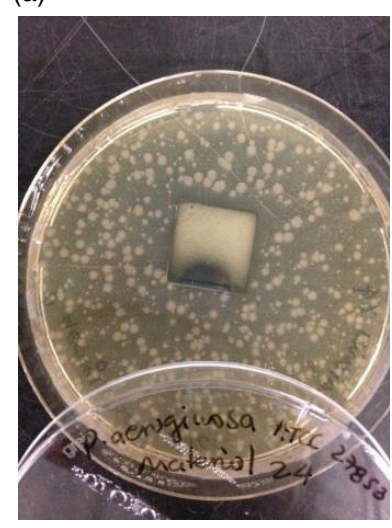

(b)

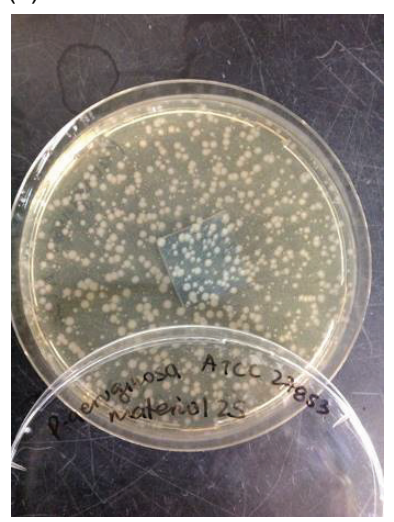

(c)

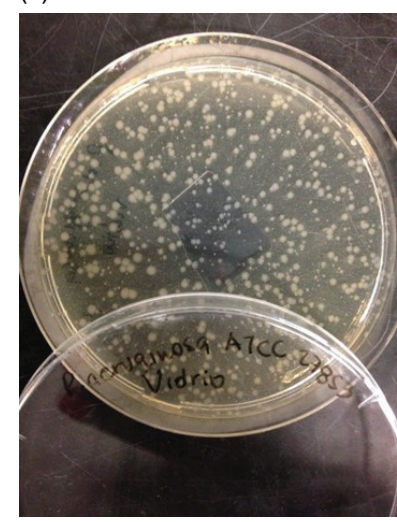

FIGURA 9. Inhibición del crecimiento bacteriano cultivos de P. aeruginosa. Fotografías: a) recubrimiento TaN(Ag)-3 tratado térmicamente a $200^{\circ} \mathrm{C}$ durante $4 \mathrm{~min}, \mathrm{~b}$ ) muestra de silicio sin recubrimiento y c) fragmento de vidrio.

prolongaciones, filias o pilis), mecanismos de defensa, energía superficial, grado de mojabilidad de su superficie y potencial z. El estudio de Truong et al. (2010), reveló que la superficie de la pared de la cepa $P$. aeruginosa, presenta un comportamiento moderadamente hidrofílico $\left(43 \pm 8^{\circ}\right)$, tendiendo éstas a adherirse con mayor facilidad a superficies hidrofílicas (Truong et al., 2010). Estudios previos realizados in vitro e in vivo, sugieren que cuando la plata entra en contacto con la pared celular de las bacterias tipo Gram-negativa, caso de $P$. aeruginosa, ésta interrumpe los múltiples procesos que allí se llevan a cabo, conduciendo a la producción de especies oxígeno-reactivas permitiendo la permeación de la membrana del microorganismo (Morones-Ramirez et al., 2013). 
(a)

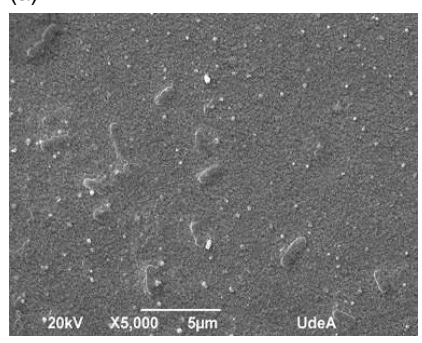

(b)

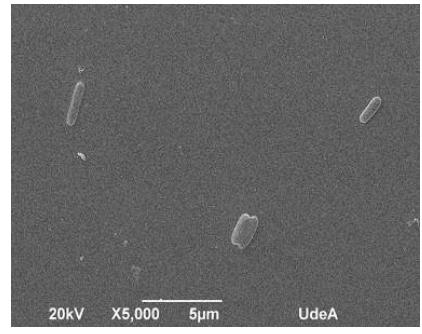

(c)

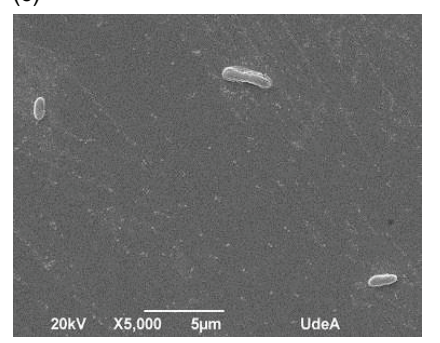

Figura 10. Prueba de adherencia en materiales expuestos a $P$. aeruginosa ATCC27853. Micrografías: a) recubrimiento TaN(Ag)-3 con tratamiento térmico, b) muestra de silicio sin recubrimiento y c) fragmento de vidrio.

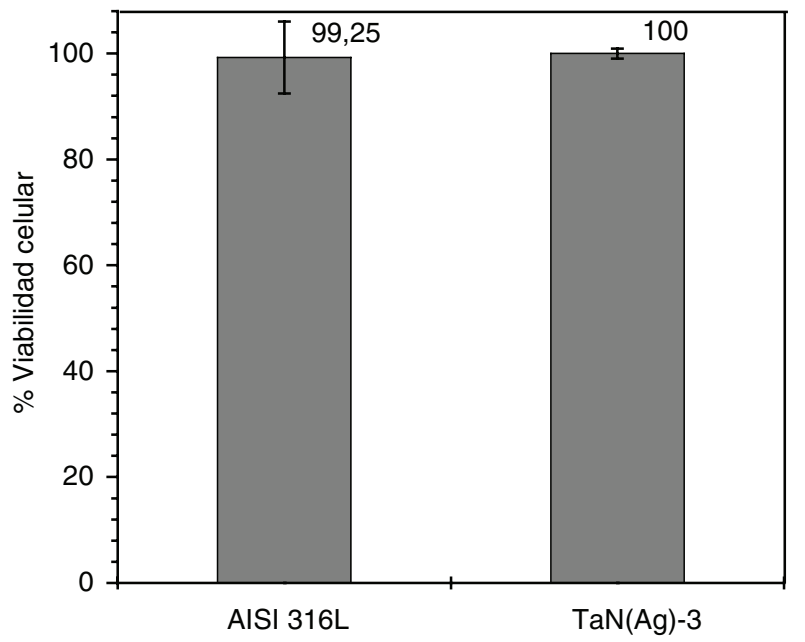

FIGURA 11. Efecto del recubrimiento TaN(Ag)-3 y del acero AISI 316L en la viabilidad celular de osteoblastos humanos.

\subsubsection{Citotoxicidad}

Acorde a la evaluación de citotoxicidad mediante el método MTT, utilizando Osteoblastos humanos del tipo Saos-2, el recubrimiento con TaN(Ag)-3 no tuvo efecto citotóxico sobre las células Saos-2, donde un 100\% de la población sobrevivió durante el ensayo. Para el acero inoxidable AISI 316L, el porcentaje de viabilidad es un poco menor (Fig. 11). Estos resultados sugieren que el recubrimiento $\mathrm{TaN}(\mathrm{Ag})-3$ es potencialmente no citotóxico.

\section{CONCLUSIONES}

- La adición de nanopartículas de plata al sistema $\mathrm{TaN}$ influye notoriamente sobre las propiedades microestructurales, mecánicas, tribológicas y biológicas del compuesto $\mathrm{TaN}(\mathrm{Ag})$. El mejor balance entre las propiedades mecánicas y tribológicas de los recubrimientos compuestos depositados se logró con la muestra TaN(Ag)-3 con un contenido de $\mathrm{Ag}$ de $12,7 \%$ antes del tratamiento térmico. Esta muestra se sometió a una serie de tratamientos térmicos entre 175 y $275^{\circ} \mathrm{C}$ durante $4 \mathrm{~min}$, presentando a $200{ }^{\circ} \mathrm{C}$ la mejor relación de tamaño/densidad de distribución de las nanopartículas de plata sobre la superficie del recubrimiento, así como también el mejor balance entre dureza y resistencia al desgaste.

- Acorde a los ensayos de inhibición y adherencia bacteriana frente a la bacteria $P$. aeruginosa y a la evaluación de citotoxicidad con osteoblastos humanos por el método $\mathrm{MTT}$, el recubrimiento TaN(Ag)-3 tratado térmicamente a $200{ }^{\circ} \mathrm{C}$ y $4 \mathrm{~min}$ de sostenimiento presentó un importante efecto bactericida y bacteriostático para el tiempo de evaluación de 24 h, así como apropiada biocompatibilidad y no toxicidad en un periodo de $72 \mathrm{~h}$, expresado en una viabilidad celular del 100\%.

- Con base en éstos resultados, el recubrimiento $\mathrm{TaN}(\mathrm{Ag})-3$ podría ser aplicado como recubrimiento protector frente al desgaste y con un elevado efecto bactericida frente a la bacteria $P$. aeruginosa en implantes dentales e implantes ortopédicos, entre otros.

\section{AGRADECIMIENTOS}

Los autores agradecen al Departamento Administrativo de Ciencia, Tecnología e Innovación -COLCIENCIAS, por la financiación de este proyecto (CT-0940-2012) y a la Universidad de Antioquia.

\section{REFRENCIAS}

Baghriche, O., Kiwi, J., Pulgarin, C., Sanjinés, R. (2012). Antibacterial Ag-ZrN surfaces promoted by subnanometric ZrN-Clusters deposited by reactive pulsed magnetron sputtering. J. Photoch. Photobio. A 229 (1), 39-45. http:// dx.doi.org/10.1016/j.jphotochem.2011.12.004.

Bai, Y., Yan, L., Wang, J., Zhigang, Y., Nuofu, Ch., Fuzhi, W., Zhan'ao, T. (2016). Tailoring Film Agglomeration for Preparation of Silver Nanoparticles with Controlled Morphology. Mater. Design 103, 315-320. http://dx.doi. org/10.1016/j.matdes.2016.04.081.

Bhatnagar, M., Mukesh, R., Jolley, K., Lloyd, A., Smith, R., Mukherjee, S. (2017). Thermal dynamics of silver clusters grown on rippled silica surfaces. Nucl. Instrum. Meth. B 393, 5-12. http://dx.doi.org/10.1016/j.nimb.2016.10.005.

Bowker, M. (2009). A Prospective: Surface Science and Catalysis at the Nanoscale. Surf. Sci. 603 (16), 2359-2362. http:// dx.doi.org/10.1016/j.susc.2009.06.017.

Chang, Y., Chih-Ho, L., Hsu, J.T., Tang, Ch.H., Liao, W.Ch., Huang, H.L (2012). Antibacterial Properties and Human 
Gingival Fibroblast Cell Compatibility of $\mathrm{TiO}_{2} / \mathrm{Ag}$ Compound Coatings and $\mathrm{ZnO}$ Films on Titanium-Based Material. Clin. Oral Investig. 16 (1), 95-100. http://dx.doi. org/10.1007/s00784-010-0504-9.

Chernousova, S., Epple, M. (2013). Silver as Antibacterial Agent: Ion, Nanoparticle, and Metal. Angew. ChemGer. Edit. 52 (6), 1636-1653. http://dx.doi.org/10.1002/ anie. 201205923 .

Echeverrigaray, F.G., Echeverrigaray, S., Delamare, A.P.L., Wanke, C.H., Figueroa, C.A., Baumvol, I.J.R., Aguzzoli, C. (2016). Antibacterial Properties Obtained by LowEnergy Silver Implantation in Stainless Steel Surfaces. Surf. Coat. Tech. 307 (Part A), 345-351. http://dx.doi. org/10.1016/j.surfcoat.2016.09.005.

Falconer, J.L., Grainger, D.W. (2017). Silver Antimicrobial Biomaterials. In Reference Module in Mat. Sci. Mater. Eng. http://dx.doi.org/10.1016/B978-0-12-803581-8.09293-6.

Gopinath, V., Velusamy, P. (2013). Extracellular biosynthesis of silver nanoparticles using bacillus Sp. GP-23 and evaluation of their antifungal activity towards Fusarium oxysporum. Spectrochim. Acta A-M 106, 170-174. http://dx.doi. org/10.1016/j.saa.2012.12.087.

Jiang, Y., Yin, Y.J., Zha, X.Ch., Dou, X.Q., Feng, Ch.L. (2016). Wettability Regulated Gram-Negative Bacterial Adhesion on Biomimetic Hierarchical Structures. Chinese Chem. Lett. 5-9. http://dx.doi.org/10.1016/j.cclet.2016.08.002.

Liskiewicz, T., Fouvry, S., Wendler, B. (2005). Development of a Wohler-like approach to quantify the $\mathrm{Ti}(\mathrm{CxNy})$ coatings durability under oscillating sliding conditions. Wear 259 (7-12), 835-841. http://dx.doi.org/10.1016/j. wear.2005.02.071.

Liu, X., Iamvasant, C., Liu, C., Matthews, A., Leyland, A. (2017). CrCuAgN PVD Nanocomposite Coatings: Effects of Annealing on Coating Morphology and Nanostructure. Appl. Surf. Sci. 392, 732-746. http://dx.doi.org/10.1016/j. apsusc.2016.09.011.

Madhuree, K., Pandey, S., Giri, V.P., Bhattacharya, A., Shukla, R., Mishra, A., Nautiyal, C.S. (2016). Tailoring Shape and Size of Biogenic Silver Nanoparticles to Enhance Antimicrobial Efficacy against MDR Bacteria. (In Press) Microb. Pathogenesis. http://dx.doi.org/10.1016/j. micpath.2016.11.012.

Manninen, N.K., Escobar G.R, Benito, N., Figueiredo, N.M., Cavaleiro, A., Palacio, C., Carvalho, S. (2011). Ag-Ti $(\mathrm{C}, \mathrm{N})$ Based Coatings for Biomedical Applications : Influence of Silver Content on the Structural Properties. J. Phys. D Appl. Phys. 44 (37), 375501. https://doi. org/10.1088/0022-3727/44/37/375501.

Marques, S.M., Rico, P., Carvalho, I., Gómez Ribelles, J.L., Fialho, L., Lanceros-Méndez, S., Henriques, M., Carvalho, S. (2016). MC3T3-E1 Cell Response to Ti 1- X Ag $\mathrm{X}$ and $\mathrm{Ag}$-TiN X Electrodes Deposited on Piezoelectric
Poly(vinylidene Fluoride) Substrates for Sensor Applications. Appl. Mater. Interfaces 8 (6), 4199-4207. http:// dx.doi.org/10.1021/acsami.5b11922.

Misra, S.K., Dybowska, A., Berhanu, D., Luoma, S.N., ValsamiJones, E. (2012). The complexity of nanoparticle dissolution and its importance in nanotoxicological studies. Sci. Total Environ. 438, 225-232. http://dx.doi.org/10.1016/j. scitotenv.2012.08.066.

Morones-Ramirez, J.R., Winkler, J.A., Spina, C.S., Collins. J. J. (2013). Silver Enhances Antibiotic Activity Against GramNegative Bacteria. Sci. Transl. Med. 5 (190), 1-11. http:/l dx.doi.org/10.1126/scitranslmed.3006276.

Muratore, C., Hu, J.J., Voevodin, A.A. (2007). Adaptive nanocomposite coatings with a titanium nitride diffusion barrier mask for high-temperature tribological applications. Thin Solid Films 515 (7-8), 3638-3643. http://dx.doi. org/10.1016/j.tsf.2006.09.051.

Rycenga, M., Cobley, C.M., Zeng, J., Weiyang, L., Moran, C.H., Zhang, Q., Qin, D., Xia, Y. (2011). Controlling the Synthesis and Assembly of Silver Nanostructures for Plasmonic Applications. Chem. Rev. 111 (6), 3669-3712. http://dx.doi. org/10.1021/cr100275d.

Tallósy, S.P., Janovák, L., Nagy, E., Deák, A., Juhász, A., Csapó, E., Buzás, N., Dékány, I. (2016). Adhesion and Inactivation of Gram-Negative and Gram-Positive Bacteria on Photoreactive $\mathrm{TiO}_{2} /$ polymer and Ag-TiO $/$ polymer Nanohybrid Films. Appl. Surf. Sci. 371, 139-150. http://dx.doi. org/10.1016/j.apsusc.2016.02.202.

Taoyu, W., Stylios, G.K., Giannoudi, M., Giannoudis, P.V. (2015). Investigating a New Drug Delivery Nano Composite Membrane System Based on PVA/PCL and PVA/ HA(PEG) for the Controlled Release of Biopharmaceuticals for Bone Infections. Injury 46, 39-43. http://dx.doi. org/10.1016/S0020-1383(15)30053-X.

Tianlu, Z., Wang, L., Chen, Q., Chen, Ch. (2014). Cytotoxic Potential of Silver Nanoparticles. Yonsei Med. J. 55, 283-291. http://dx.doi.org/10.3349/ymj.2014.55.2.283.

Truong, V.K., Lapovok, R., Estrin, Y.S., Stuart Rundell, J., Wang, Y., Fluke, C.J, Crawford, R.J., Ivanova, E.P. (2010). The influence of nano-scale surface roughness on bacterial adhesion to ultrafine-grained titanium. Biomaterials 31 (13), 3674-3683. http://dx.doi.org/10.1016/j. biomaterials.2010.01.071.

Wang, J., Kaplan, J.A., Colson, Y.L., Grinstaff, M.W. (2016). Mechanoresponsive materials for drug delivery: harnessing forces for controlled release. Adv. Drug Deliver. Rev. 108, 68-82. http://dx.doi.org/10.1016/j.addr.2016.11.001.

Wei, Z., Chu, P.K. (2008). Enhancement of Antibacterial Properties and Biocompatibility of Polyethylene by Silver and Copper Plasma Immersion Ion Implantation. Surf. Coat. Tech. 203, 909-912. http://dx.doi.org/10.1016/j. surfcoat.2008.08.023. 